\title{
Comparison of different retreatment techniques and root canal sealers: a scanning electron microscopic study
}

\begin{abstract}
Neslihan SIMSEK(a)
Ali KELES(a)

Fuat AHMETOGLU(a)

Mevlüt Sinan OCAK(a)

Saim YOLOGLU(b)
\end{abstract}

(a) Department of Endodontics, Faculty of Dentistry, Inonu University, Malatya, Turkey.

(b) Department of Bioistatistics, Faculty of Medicine, Inonu University.
Declaration of Interests: The authors certify that they have no commercial or associative interest that represents a conflict of interest in connection with the manuscript.

\section{Corresponding Author:}

Neslihan Simsek

E-mail: neslihan.akdemir@inonu.edu.tr

DOI: 10.1590/1807-3107BOR-2014.vol28.0006 Epub: XXXXX, 2014

Submitted: Feb 16, 2013

Accepted for publication: Dec 11, 2013

Last revision: Jan 22, 2014

\begin{abstract}
The aim of this study was to evaluate the effectiveness of two retreatment techniques, in terms of the operating time and scanning electron microscopy (SEM) results, in removing three different root canal sealers from root canals that were previously filled with gutta-percha. Sixty extracted single-rooted human premolars were divided into three groups and filled with iRoot SP, MM Seal, and AH Plus sealers, along with gutta-percha, through a lateral compaction technique. Root canal fillings of the samples were removed by ESI ultrasonic tips or REndo files. The time to reach the working length was recorded. Longitudinally sectioned samples were examined under SEM magnification. Each picture was evaluated in terms of the residual debris. Data were statistically analyzed with the Kruskall-Wallis test. No statistically significant differences were found in terms of operating time $(p>0.05)$. Significant differences in the number of debris-free dentinal tubules were found among the root canal thirds, but this finding was not influenced by the experimental group $(p<0.05)$. Resin sealer tags were observed inside the dentinal tubules in the MM Seal group. Under the conditions of this study, it may be established that there was no difference among the sealers and retreatment techniques.
\end{abstract}

Keywords: Endodontics; Retreatment; Microscopy, Electron, Scanning.

\section{Introduction}

The retreatment of previously treated root canals is a common procedure in endodontics. Successful retreatment requires the effective elimination of necrotic tissue and microorganism-infected materials, such as gutta-percha and sealer. The clinical success rate of retreatment has been estimated to vary between $50 \%$ and $90 \%$.

Retreatment involves removing the previous root canal filling and performing advanced shaping, cleaning, and filling operations. ${ }^{1}$ Root canal fillings can be removed with solvents, heating apparatuses, lasers, hand or rotary files, or ultrasonic instruments. ${ }^{2}$ However, well-compacted fillings offer resistance to instruments, and the subsequently inadequate elimination of materials can lead to restricted access to the apical foramen. This condition can impair the root canal disinfection, reforming process, and cleaning time. After gutta-percha removal, open dentinal tubules are necessary in order to eradicate bacteria using irrigants. However, several studies ${ }^{2,3,4}$ have shown that residual 
debris remains on the root canal walls after treatment, regardless of the instrumentation and type of filling that are used.

Endodontic treatment has improved with the development of better ultrasonic tips and nickeltitanium (NiTi) instruments. ${ }^{5}$ Ultrasonic systems are widely used in root canal treatment, to facilitate the removal of broken files from the root canal and to prepare root-end cavities. ${ }^{6}$ However, the process of completely removing gutta-percha and sealer with ultrasonic tips has not been fully explored. ${ }^{3}$

Of the many materials used for filling root canals, gutta-percha is the most commonly used, in conjunction with various sealers. ${ }^{7}$ According to the manufacturer, iRoot SP is a new calcium silicate-based root canal sealer that is radiopaque and insoluble. It contains calcium, calcium phosphate, calcium hydroxide, and zirconium oxide, without aluminum. iRoot $\mathrm{SP}$ does not require a supplementary curing mediator or mixing. It offers a consistent, uniform product for filling root canals with or without gutta-percha points. It is a premixed, ready-to-use injectable sealer that has been developed for permanent canal filling. ${ }^{8}$ However, the properties of retreatment using iRoot SP are not clear.

Epoxy resin-based cements perform well as root canal sealers. AH Plus (Denstply DeTrey, Konstanz, Germany) is a two-component paste root canal sealer that is based on a polymerization reaction of epoxy resin amines. It is composed of diepoxide, calcium tungstate, zirconium oxide, aerosol, 1-adamantane amine, TCD-diamine, dibenzyldiamine, aminoadamantane, and pigments. ${ }^{9}$ Another epoxy resin-based root canal sealer, MM Seal (Micro-Mega, Besançon, France), is packaged in a dual syringe. It is used for the permanent filling of root canals with gutta-percha. MM Seal is composed of epoxy polymer resin, ethylene glycol salicylate, calcium phosphate, bismuth subcarbonate and oxide components. ${ }^{10}$

The aim of this study was to evaluate the effectiveness, in terms of the operating time and scanning electron microscopy (SEM) results, of two different retreatment techniques (ESI ultrasonic tips and R-Endo files) in removing three different sealers (AH Plus, iRoot SP, and MM Seal) from root canals that had been previously filled with gutta-percha.

\section{Methodology Rootcanal preparation}

After approval by the ethics committee (2012/139), 60 single-rooted and straight single-canal premolars extracted for periodontal reasons were used in this study. Teeth were stored in purified filtered water until they were ready for use. The working length $(\mathrm{WL})$ was set at $14 \mathrm{~mm}$. The root canals were prepared with HERO Shaper rotary files (Micro-Mega, Besançon, France) with the crown-down technique, according to the manufacturer's instructions. Files were used to file no. 30 at $300 \mathrm{rpm}$. With each file change, the canal was irrigated with $2 \mathrm{~mL}$ of a $2.5 \%$ $\mathrm{NaOCl}$. After completion, $2 \mathrm{~mL}$ of $17 \%$ EDTA were applied for $60 \mathrm{~s}$, followed by a final rinse with $2 \mathrm{~mL}$ of $2.5 \% \mathrm{NaOCl}$. Root canals were dried with paper points before filling.

\section{Root canal filling}

The roots were randomly divided into 6 groups of 10 roots each: Groups 1 and 2 were filled with guttapercha and AH Plus; Groups 3 and 4 were filled with gutta-percha and iRoot SP (Innovative BioCeramix Inc., Vancouver, Canada); and Groups 5 and 6 were filled with gutta-percha and MMSeal. All roots were filled via the cold lateral compaction technique. Mesiodistal and buccolingual radiographs were taken to check the quality of the fillings. Samples were stored at $37^{\circ} \mathrm{C}$ in $100 \%$ humidity for 1 week.

\section{Retreatment technique}

For preliminary treatment, size 3 and 4 Gates Glidden drills (Dentsply Maillefer, Ballaigues, Switzerland) were used to remove the fillings from all canals at the level of the coronal third. To soften the gutta-percha, $0.1 \mathrm{~mL}$ of chloroform was applied to and kept in the coronal third for $1 \mathrm{~min}$. Groups 1,3 , and 5 were re-treated with R-Endo files (NiTi retreatment groups), and Groups 2, 4 and 6 were re-treated with ultrasound ESI tips (ultrasonic retreatment groups).

NiTi retreatment groups. R-Endo files were used at a constant speed of $300 \mathrm{rpm}$ with a low-torque hand 
piece powered by an electric motor $(W \& H$, Bürmoos, Austria). Files were used to remove the filling material as follows: R1 (15 mm, 25.08) for the cervical and middle thirds, and R2 (19 mm, 25.06) and R3 $(23 \mathrm{~mm}$, 25.04) for the apical third until the WL was reached.

Ultrasonic retreatment groups. ESI ultrasound tips of different sizes (15-35) attached to a miniMaster Piezon (EMS, Nyon, Switzerland) were used in a circumferential motion until the WL was achieved. The master tip at WL was no. 35.

For all groups, with each file change, the root canal was irrigated with $2 \mathrm{~mL}$ of $2.5 \% \mathrm{NaOCl}$. After completion, $2 \mathrm{~mL}$ of $17 \%$ EDTA were applied for $60 \mathrm{~s}$, followed by a final rinse with $2 \mathrm{~mL}$ of $2.5 \%$ $\mathrm{NaOCl}$. Retreatment was completed when the WL was achieved and the root canals were smooth and free of visible debris.

\section{Time}

The total time of the procedure included irrigation and file changes. The time it took to reach the WL was recorded as T1. The time it took from starting to remove the filling material to completing the cleaning process was recorded as T2. The time was recorded in seconds and minutes.

\section{SEM analysis}

Each sample was grooved buccolingually using a diamond disc and split into two halves with a stainless steel chisel. After a general survey of the root canal walls from the apex to the coronal part, three SEM (LEO EVO 40, Cambridge, United Kingdom) digital images were taken at magnifications of $\times 100$ and $\times 2000$. To evaluate the residual debris, the opened and closed dentinal tubules (coronal, middle, and apical) were counted using Adobe Photoshop CS3 (Adobe Systems Inc., San Jose, USA). ${ }^{11,12}$ The images were assessed by the same operator.

\section{Statistical analysis}

Statistical analysis was performed using SPSS for Windows (version 15.0, SPSS Inc., Chicago, USA). Each continuous variable is reported as the mean $(X) \pm$ standard deviation (SD) or standard error (SE). Each categorical variable is reported as a number. The continuous variables showed nor- mal distributions in the groups, according to the results of the Shapiro-Wilk test $(p>0.05)$. Paired and unpaired $t$-tests were performed to evaluate the change in operating time of the root canal sealer and the retreatment technique for each group. The Kruskall-Wallis test was performed to compare the differences among the three sealers and the two retreatment methods. A value of $p<0.05$ was considered significant.

\section{Results}

\section{Time required for material removal}

There was no significant difference in $\mathrm{T} 1$ or $\mathrm{T} 2$ using R-Endo versus ultrasonic tips $(p>0.05)$ (Table 1). There was no difference in the time required to remove AH Plus, iRoot SP, or MM Seal $(p>0.05)$ (Table 2). The increasing time from T1 to T2 was significant in all groups.

\section{Evaluation of residual debris}

Results of the SEM analysis for open dentinal tubules are summarized in Tables 3 and 4 . None of the retreatment techniques was able to remove debris in the root thirds completely, regardless of the sealer (Figures 1, 2, and 3). However, comparing among the root thirds, there were fewer open dentinal tubules in the apical third, and a larger number of clear dentinal tubules in the coronal third. In several samples of the MM Seal group, dentinal tubule orifices were filled by a resin sealer (Figure 4).

Table 1. Analysis of the retreatment techniques with respect to changing time.

\begin{tabular}{lccc}
\hline $\begin{array}{l}\text { Retreatment } \\
\text { Techniques }\end{array}$ & $\begin{array}{c}\text { T1 time } \\
\mathrm{X} \pm \mathrm{SD}\end{array}$ & $\begin{array}{c}\text { T2 time } \\
\mathrm{X} \pm \mathrm{SD}\end{array}$ & $\mathrm{p}$ \\
\hline R-Endo & $2.36 \pm 0.87$ & $3.98 \pm 1.09$ & 0.0001 \\
Ultrasonic & $2.64 \pm 1.51$ & $4.44 \pm 1.38$ & 0.0001 \\
\hline
\end{tabular}

Table 2. Analysis of the sealers with respect to changing time

\begin{tabular}{lccc}
\hline $\begin{array}{l}\text { Root Canal } \\
\text { Sealers }\end{array}$ & $\begin{array}{c}\text { T1 time } \\
\mathrm{X} \pm \mathrm{SD}\end{array}$ & $\begin{array}{c}\text { T2 time } \\
\mathrm{X} \pm \mathrm{SD}\end{array}$ & $\mathrm{p}$ \\
\hline AH Plus & $2.92 \pm 0.97$ & $4.43 \pm 0.78$ & 0.0001 \\
iRoot SP & $2.04 \pm 1.08$ & $3.95 \pm 1.44$ & 0.0001 \\
MM Seal & $2.54 \pm 1.47$ & $4.26 \pm 1.45$ & 0.0001 \\
\hline
\end{tabular}


Table 3. Means of the number of dentinal tubules free of debris in R-Endo groups

\begin{tabular}{|c|c|c|c|c|}
\hline & Third & $\begin{array}{c}\text { iRoot SP } \\
X \pm S E \\
\text { Median (Range) }\end{array}$ & $\begin{array}{c}\text { AH Plus } \\
\mathrm{X} \pm \mathrm{SE} \\
\text { Median (Range) }\end{array}$ & $\begin{array}{c}\text { MM Seal } \\
\mathrm{X} \pm \mathrm{SE} \\
\text { Median (Range) }\end{array}$ \\
\hline \multirow[t]{3}{*}{ Number of tubules } & Coronal & $\begin{array}{c}653.3 \pm 73.8 \\
630.5(721)\end{array}$ & $\begin{array}{c}682.6 \pm 85.0 \\
664(848)\end{array}$ & $\begin{array}{c}608.2 \pm 163.8 \\
503.5(1717)\end{array}$ \\
\hline & Middle & $\begin{array}{c}267.7 \pm 86.4 \\
188(884)\end{array}$ & $\begin{array}{c}162.1 \pm 71.2 \\
48.5(600)\end{array}$ & $\begin{array}{c}164.9 \pm 66.2 \\
48(566)\end{array}$ \\
\hline & Apical & $\begin{array}{c}29.7 \pm 29.7 \\
0(297)\end{array}$ & $\begin{array}{c}89.4 \pm 45.0 \\
0(342)\end{array}$ & $\begin{array}{c}162.1 \pm 127.1 \\
0(1260)\end{array}$ \\
\hline Total & & $p=0.0001$ & $p=0.0001$ & $p=0.0002$ \\
\hline
\end{tabular}

Table 4. Means of the number of dentinal tubules free of debris in ultrasonic groups

\begin{tabular}{|c|c|c|c|c|}
\hline & Third & $\begin{array}{c}\text { iRoot SP } \\
\mathrm{X} \pm \mathrm{SE} \\
\text { Median (Range) }\end{array}$ & $\begin{array}{c}\text { AH Plus } \\
\mathrm{X} \pm \mathrm{SE} \\
\text { Median (Range) }\end{array}$ & $\begin{array}{c}\text { MM Seal } \\
X \pm S E \\
\text { Median (Range) }\end{array}$ \\
\hline \multirow[t]{3}{*}{ Number of tubules } & Coronal & $\begin{array}{c}576.7 \pm 199.9 \\
603.0(680)\end{array}$ & $\begin{array}{c}722.4 \pm 74.2 \\
674(614)\end{array}$ & $\begin{array}{c}799.5 \pm 136.0 \\
747.0(1490)\end{array}$ \\
\hline & Middle & $\begin{array}{c}165.5 \pm 56.2 \\
77.5(450)\end{array}$ & $\begin{array}{c}157.4 \pm 55.1 \\
77.5(435)\end{array}$ & $\begin{array}{c}152.2 \pm 42.0 \\
96.0(320)\end{array}$ \\
\hline & Apical & $\begin{array}{c}137.0 \pm 118.6 \\
0(1200)\end{array}$ & $\begin{array}{c}26.9 \pm 14.3 \\
6.5(144)\end{array}$ & $\begin{array}{c}55.9 \pm 25.1 \\
13.0(200)\end{array}$ \\
\hline Total & & $p=0.001$ & $p=0.0001$ & $p=0.0001$ \\
\hline
\end{tabular}

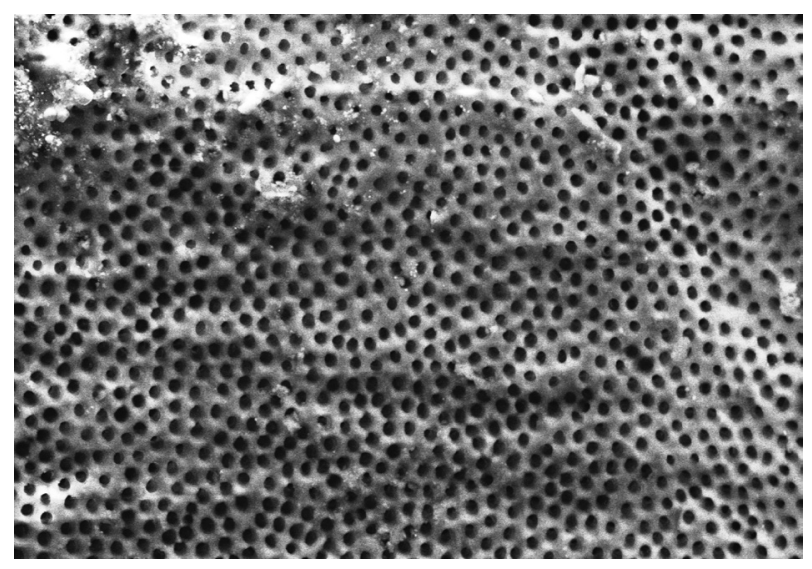

$10 \mu \mathrm{m} \quad \mathrm{Mag}=2.00 \mathrm{KX} \quad \mathrm{WD}=13 \mathrm{~mm} \quad \mathrm{EHT}=20.00 \mathrm{kV}$ Signal $\mathrm{A}=\mathrm{SE} 1 \quad$ IBTAM

Figure 1. Representative SEM image at $\times 2000$ magnification for coronal third. All dentinal tubules were open.

\section{Discussion}

The most important reason for renewed endodontic treatment is to remove root canal fillings completely, in order to ensure disinfection of the canal and healing of the periapical tissues. ${ }^{2}$ Gutta-percha can be dissolved using chloroform, carbon disulfide, benzene,

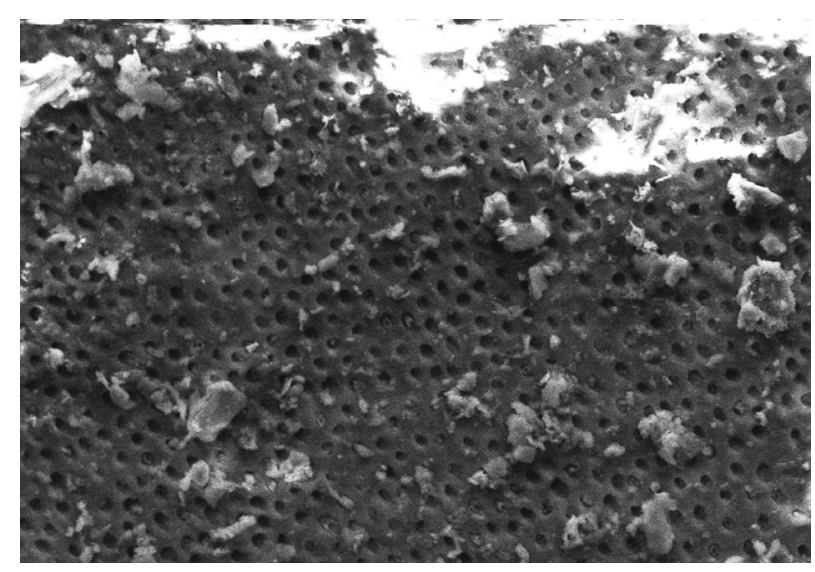

$10 \mu \mathrm{m}$ Mag $=2.00 \mathrm{KX} W D=13 \mathrm{~mm} \quad E H T=20.00 \mathrm{kV}$ Signal $A=S E 1 \quad$ IBTAM

Figure 2. Representative SEM image at $\times 2000$ magnification for middle third. Partially dentinal tubules are open.

xylene, essential oils, methyl chloroform, halothane, white turpentine, carbon tetrachloride, and eucalyptus oil. ${ }^{13}$ We used chloroform to soften the well-condensed filling material. However, the pressure of the file might have penetrated the softened material in the dentinal tubules, which were cleaned with EDTA and $\mathrm{NaOCl}^{4}$ 


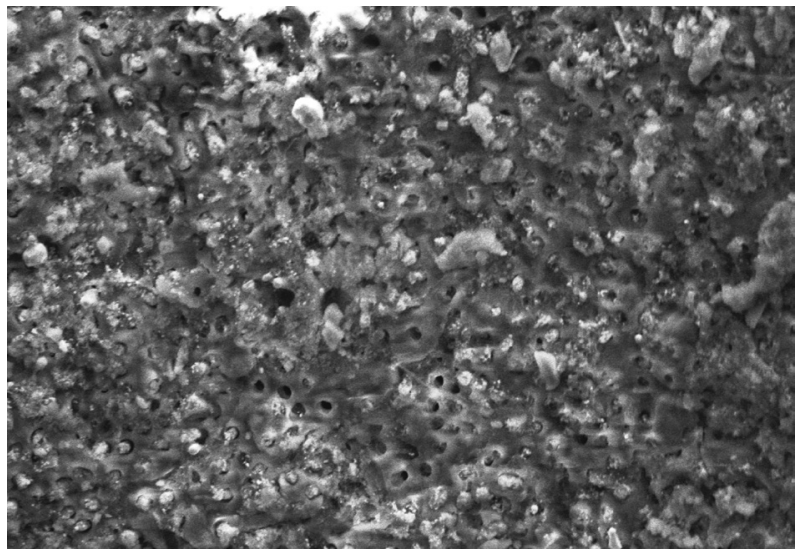

$10 \mu \mathrm{m} \quad$ Mag $=2.00 \mathrm{KX} \quad W D=13 \mathrm{~mm} \quad \mathrm{EHT}=20.00 \mathrm{kV}$ Signal $A=S E 1 \quad$ IBTAM

Figure 3. Representative SEM image at $\times 2000$ magnification for apical third. Most of dentinal tubules are close.

Various techniques have been used to remove gutta-percha from root canals, including rotary files ${ }^{14}$ and ultrasonic tips. ${ }^{15}$ Ultrasonic tips are excellent tools to use for the coronal half of the root canal system, but the curve of the apical part of the canal can cause difficulty. Therefore, ultrasonic tips should be used for the remaining sections of the canal curvature. ${ }^{3}$ In this study, we used straight root canals. Many commercially available ultrasonic tips are available, with different shapes, designs, and compositions (e.g., stainless steel, titanium alloys, diamonds, zircons, etc.). We used stainless steel ultrasonic tips compatible with the root anatomy to remove residual filling material without damaging the inner walls of the roots. ${ }^{16}$ These tips were not used in retreatment techniques with iRoot SP, which performed as a sealer.

Rotary NiTi systems are faster than hand instruments, such as R-Endo files. The use of rotary instruments in root canal retreatment might reduce patient and operator fatigue. ${ }^{17}$ However, there is insufficient information in the literature to compare the use of R-Endo files to ultrasonic tips in terms of retreatment operating time or remnants of debris. Both the R-Endo and ultrasonic tips used in the present study completed the retreatment within similar intervals of time.

The iRoot SP seal is a relatively new sealer that contains calcium silicate, which requires the presence of water to set. The results obtained when using iRoot SP were similar to those obtained with apical

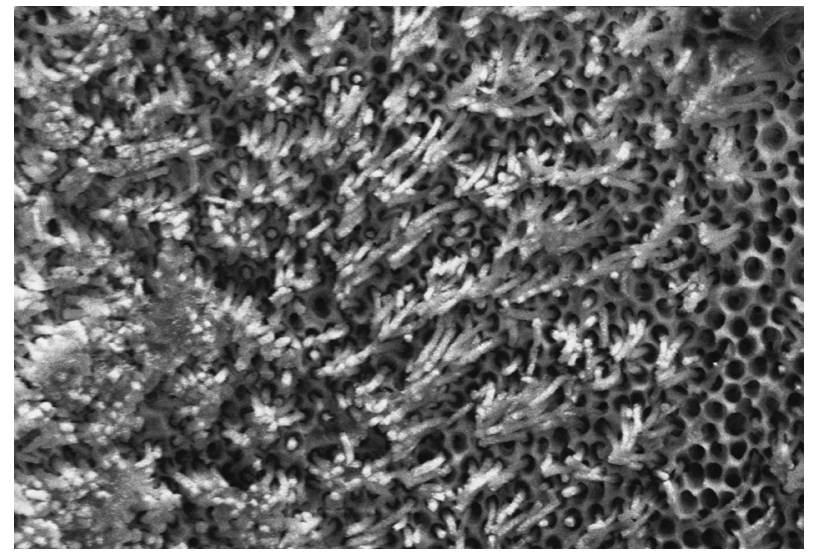

$10 \mu \mathrm{m} \quad \mathrm{Mag}=2.00 \mathrm{KX} \quad W D=12 \mathrm{~mm} \quad \mathrm{EHT}=20.00 \mathrm{kV}$ Signal $A=S E 1 \quad$ IBTAM

Figure 4. Resin sealer materials in dentinal tubule orifices in MM Seal samples

sealing using AH Plus. The bond strength ${ }^{18}$ and antimicrobial activity ${ }^{19}$ of iRoot AP have been studied; however, its effects in retreatment are not clear. Thus, this study sheds light on this issue. The adhesion properties of sealers influence the ease with which they can be removed. The push-out bond strength of iRoot SP is reported to be similar to that of $\mathrm{AH}$ Plus. ${ }^{18}$ In this study, iRoot SP samples did not show a difference compared to the AH Plus samples in terms of remaining material.

AH Plus was selected because of its widespread use. Both AH Plus and MM Seal are epoxy resinbased sealers with comparable apical sealing abilities because of their similar chemical components..$^{10}$ After retreatment procedures, some fractured resin tags were observed in the MMSeal group samples. These results are consistent with Pirani et al. ${ }^{3}$ because both sealers are epoxy resin-based. The fractured resin tags blocked the entrance of the dentinal tubules. EDTA and $\mathrm{NaOCl}$ presumably failed to solve this issue.

In this study, residual debris was seen in all groups, which is similar to previous studies. During material removal, canals in all groups tended to amass more debris apically, regardless of the protocol or material used. This finding concurs with previous reports. ${ }^{3,14,20}$

The properties of sealers, such as their dimensional stability and resolution, may affect the duration of retreatment. ${ }^{21}$ In this study, retreatment lasted from 3 to 8 min Oliveira et al. ${ }^{14}$ did not include the changing of rotary files and irrigation procedures in the 
operation time and reported retreatment times of 2 to $4 \mathrm{~min}$. Time differences between studies could be due to the use of different root canal fillings and preparation techniques, differences in the ability of the practitioner, and the employment of solvents or burs to facilitate the entrance of the canal. Rotary systems produce heat via a specific torque force with frictional movement, which is known to facilitate the dissolution and removal of heated gutta-percha. ${ }^{22}$ In this study, the ultrasonic tips were warmed, but there was no difference between the groups in terms of the time it took to remove the gutta-percha.

Many techniques have been used to evaluate the remaining debris ${ }^{11,12,23}$ on dentin surfaces. However, only SEM permits an extremely comprehensive observation of the opened or closed dentinal tubules. ${ }^{24}$ In this study, high-resolution SEM images showed dentinal tubules free of debris. There was a difference in the number of clean dentinal tubules among the root canal thirds. The apical third presented the lowest number of clean dentinal tubules compared to the middle or coronal third, regardless of the technique or sealer used. This observation is consistent with the findings of previous studies. ${ }^{3,20}$

The coronal third showed more open tubules than the other thirds. There are two reasons for this finding. First, it is easy to clean the entire root canal. Second, the coronal part was re-treated with Gates Glidden drills. The total number of dentinal tubules in the apical third was less than the number in the middle or coronal third. This finding could reflect the physiological phenomenon of tubular sclerosis, which

\section{References}

1. Hulsmann M, Stotz S. Efficacy, cleaning ability and safety of different devices for gutta percha removal in root canal retreatment. Int Endod J. 1997 Jul;30(4):227-33.

2. Hulsmann M, Bluhm V. Efficacy, cleaning ability and safety of different rotary NiTi instruments in root canal retreatment. Int Endod J. 2004 Jul;37(7):468-76.

3. Pirani C, Pelliccioni GA, Marchionni S, Montebugnoli L, Piana G, Prati C. Effectiveness of three different retreatment techniques in canals filled with compacted gutta percha or Thermafil: a scanning electron microscope study. J Endod. 2009 Oct;35(10):1433-40. starts in the third decade of life in the apical part of the root canal and progresses coronally with age. ${ }^{25}$

Our study shows that the apical root section can be partially cleared. On the basis of this discovery, we propose a requirement to improve the size of the apical preparation when rotary instruments are used. The residual gutta-percha in the apical third was less in the R-Endo group compared to the ultrasonic group, although the difference was not statistically significant. This finding may be because of the increased tip diameter of the R-Endo files, or because the instruments were designed specifically for removing material. Additionally, the R-Endo files were employed through a crown-down approach, in which the filling material is removed from the coronal third. This method may explain why instrumentation was more efficient in the apical third. ${ }^{26}$

\section{Conclusions}

Both R-Endo and ultrasonic tips performed similarly in terms of operating time. All of the retreatment systems in each group left remnants, regardless of the sealer. In all groups, apical tubules were less clear than other parts of the root.

\section{Acknowledgements}

This project was supported by Inonu University, Scientific Research Projects Unit (201178).

This study was presented as an oral presentation at Turkish Endodontic Society, 11. International Congress, April 2012, Istanbul, Turkey.

The authors deny any conflict of interest.

4. Sae-Lim V, Rajamanickam I, Lim BK, Lee HL. Effectiveness of ProFile.04 taper rotary instruments in endodontic retreatment. J Endod. 2000 Feb;26(2):100-4.

5. Plotino G, Pameijer CH, Grande NM, Somma F. Ultrasonics in endodontics: a review of the literature. J Endod. 2007 Feb;33(2):81-95.

6. Ruddle CJ. Nonsurgical retreatment. J Endod. 2004 Dec;30(12):827-45.

7. Kratchman SI. Obturation of the root canal system. Dent Clin North Am. 2004 Jan;48(1):203-15.

8. Zhang W, Li Z, Peng B. Assessment of a new root canal sealer's apical sealing ability. Oral Surg Oral Med Oral Pathol Oral Radiol Endod. 2009 Jun;107(6):e79-82. 
9. Cohen BI, Pagnillo MK, Musikant BL, Deutsch AS. An in vitro study of the cytotoxicity of two root canal sealers. J Endod. 2000 Apr;26(4):228-9.

10. Bodrumlu E, Avsar A, Meydan AD, Tuloglu N. Can radiotherapy affect the apical sealing ability of resin-based root canal sealers? J Am Dent Assoc. 2009 Mar;140(3):326-30.

11. Horvath SD, Altenburger MJ, Naumann M, Wolkewitz M, Schirrmeister JF. Cleanliness of dentinal tubules following gutta-percha removal with and without solvents: a scanning electron microscopic study. Int Endod J. 2009 Nov;42(11):1032-8.

12. Scelza MF, Coil JM, Maciel AC, Oliveira LR, Scelza P. Comparative SEM evaluation of three solvents used in endodontic retreatment: an ex vivo study. J Appl Oral Sci. 2008 Jan-Feb;16(1):24-9.

13. McDonald MN, Vire DE. Chloroform in the endodontic operatory. J Endod. 1992 Jun;18(6):301-3.

14. Oliveira DP, Barbizam JV, Trope M, Teixeira FB. Comparison between gutta percha and resilon removal using two different techniques in endodontic retreatment. J Endod. 2006 Apr;32(4):362-4.

15. Moshonov J, Trope M, Friedman S. Retreatment efficacy 3 months after obturation using glass ionomer cement, zinc oxide-eugenol, and epoxy resin sealers. J Endod. 1994 Feb;20(2):90-2.

16. Mello Junior JE, Cunha RS, Bueno CE, Zuolo ML. Retreatment efficacy of gutta percha removal using a clinical microscope and ultrasonic instruments: part I--an ex vivo study. Oral Surg Oral Med Oral Pathol Oral Radiol Endod. 2009 Jul;108(1):e59-62.

17. Tasdemir T, Er K, Yildirim T, Celik D. Efficacy of three rotary NiTi instruments in removing gutta percha from root canals. Int Endod J. 2008 Mar;41(3):191-6.

18. Ersahan S, Aydin C. Dislocation resistance of iRoot SP, a calcium silicate-based sealer, from radicular dentine. J Endod. 2010 Dec;36(12):2000-2.
19. Zhang H, Shen Y, Ruse ND, Haapasalo M. Antibacterial activity of endodontic sealers by modified direct contact test against Enterococcus faecalis. J Endod. 2009 Jul;35(7):1051-5.

20. oschi F, Nucci C, Montebugnoli L, Marchionni S, Breschi L, Malagnino VA, et al. SEM evaluation of canal wall dentine following use of Mtwo and ProTaper NiTi rotary instruments. Int Endod J. 2004 Dec;37(12):832-9.

21. Kosti E, Lambrianidis T, Economides N, Neofitou C. Ex vivo study of the efficacy of $\mathrm{H}$-files and rotary $\mathrm{Ni}-\mathrm{Ti}$ instruments to remove gutta percha and four types of sealer. Int Endod J. 2006 Jan;39(1):48-54.

22. Betti LV, Bramante CM. Quantec SC rotary instruments versus hand files for gutta percha removal in root canal retreatment. Int Endod J. 2001 Oct;34(7):514-9.

23. Takahashi CM, Cunha RS, De Martin AS, Fontana CE, Silveira $\mathrm{CF}$, Silveira Bueno CE. In vitro evaluation of the effectiveness of ProTaper universal rotary retreatment system for gutta-percha removal with or without a solvent. J Endod. 2009 Nov;35(11):1580-3.

24. Xu LL, Zhang L, Zhou XD, Wang R, Deng YH, Huang DM. Residual filling material in dentinal tubules after gutta-percha removal observed with scanning electron microscopy. J Endod. 2012 Mar;38(3):293-6.

25. Paque F, Luder HU, Sener B, Zehnder M. Tubular sclerosis rather than the smear layer impedes dye penetration into the dentine of endodontically instrumented root canals. Int Endod J. 2006 Jan;39(1):18-25.

26. Ring J, Murray PE, Namerow KN, Moldauer BI, Garcia-Godoy F. Removing root canal obturation materials: a comparison of rotary file systems and re-treatment agents. J Am Dent Assoc. 2009 Jun;140(6):680-8. 